\title{
Characterization of Dispersive Soils
}

\author{
T. S. Umesh ${ }^{1}$, S. V. Dinesh ${ }^{1}$, Puvvadi V. Sivapullaiah ${ }^{2}$ \\ ${ }^{1}$ Department of Civil Engineering, Siddaganga Institute of Technology, Tumkur, India; ${ }^{2}$ Department of Civil Engineering, Indian \\ Institute of Science, Bangalore, India. \\ Email: t_s_umesha@yahoo.co.in, dineshsv2004@yahoo.com, siva@civil.iisc.ernet.in
}

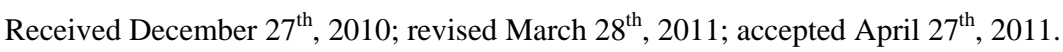

\begin{abstract}
Dispersive soils which occur in many parts of the world are easily erodible and segregate in water pose serious problems of stability of earth and earth retaining structures. The mechanism of dispersivity of soils is reasonably well understood. However there is simple method to identify the dispersivity of the soils and even more difficult to quantify the dispersivity. Visual classification, Atterberg's limits and particle size analysis do not provide sufficient basis to differentiate between dispersive clays and ordinary erosion resistant clays. Pinhole test and double hydrometer test are the only two tests that are in vogue to identify the dispersive soils. This paper explores the possibility of using other standard tests such as shrinkage limit and unconfined compressive strength tests to quantify the dispersivity of the soils. The rationale of using the methods and correlation between the dispersivity determined by various methods has been explained. It has been concluded that dispersivity ascertained from strength tests is more reliable.
\end{abstract}

Keywords: Atterberg's Limit, Dispersive Soils, Particle Size Distribution, Unconfined Compression Strength

\section{Introduction}

The soils that are highly susceptible to erosion and containing high percentage of exchangeable sodium ions are called Dispersive soils. These soils are found extensively in United States, Australia, Greece, India, Latin America, South Africa and Thailand. These soils are erodible in nature and have tendency to segregate in presence of water and erode under small seepage velocity leading to problems of stability of earth and earth retaining structures. Soil dispersivity is mainly due to the presence of exchangeable sodium present in the structure. The erosion due to dispersion of soil depends on mineralogy and clay chemistry and the dissolved salts in pore water. Under saturated conditions, the attractive forces are less than the repulsive forces, and this will help the particle to segregate and to move in suspension. The dispersive mechanism have been reported by various researchers such as Sherard et al., [1], Heinzen and Arulalandan [2], Holmgren and Flanagan [3]. Many slope and earth dam failures, foundation and pavement failures have been observed in these types of soils [4]. Most of the failures in embankments, earth dams and slopes were composed of clays with low-to- medium plasticity (CL and CL-CH) that contain montmorillonite. In order to assess the extent of damage and also to plan for suitable remedy, it is necessary to characterize these soils. It is necessary to esti- mate the extent of dispersiveness so that the damage potential can be estimated. At present, dispersivity is obtained from pin hole test, double hydrometer test, crumb test etc. Though pin hole test is considered to be accurate but care has to be taken to properly simulate field condition in terms of soil state and flowing condition [5]. The crumb test indicates erodibility of clayey soil, but a dispersive soil some times give a non dispersive reaction. In double hydrometer test number of tests should be performed since soil dispersiveness can be altered over short distance in a borrow area, canal alignment, embankment etc (U.S.Department of the interior 1991).

The problems related to dispersive soils are common through out the world. Earth dams constructed on dispersive soils have suffered internal and surface erosion. The erosion features such as rill and gully marks, channels, internal cavities and tunnels with in the soil mass have been observed in natural slopes of dispersive soils. The failure of slopes due to dispersion of clay particles by seepage water along cracks, fissures and root holes are initiated by erosion of soil. Thus the failure initiated by piping makes the embankments constructed on dispersive soil susceptible [4]. Dispersive piping in dams has occurred either on the first reservoir filling or, less frequently, after raising the reservoir to highest level. Tunneling failures commence at the upstream face when the reservoir is filled for the first time, the settlement may 
accompany saturation of the soil, particularly if the soil was placed dry of optimum and not well compacted. Settlement below the phreatic surface and arching above can result in crack formation. Water moving through the cracks picks up dispersive clay particles, with the rate of removal increasing as the seepage velocity increases [5].

\section{Dispersion Phenomenon}

The clay fraction in dispersive soil that comes in contact with water behaves like a single grained particle with less electrochemical attraction and does not adhere with other soil particle. The electrical surface force (inter particle repulsive force) exceeds the Van der walls attraction and the detached clay particles are carried away causing piping in earth dams. The dispersiveness of soils is mainly due to the presence of sodium ions in the soil structure and not due to the presence of sodium in the pore water [6].

The erosion occurs when shearing stress induced by fluid flow on a surface is large enough to cause particle removal from the surface. The resistance to erosion is offered by the submerged weight of the sediment, i.e. gravity forces for non-cohesive soils. But in cohesive soil the structure of the soil and the interaction between pore and eroding fluids at the surface is the phenomenon involved in soil erosion. The amount and type of clay, $\mathrm{pH}$, organic matter, temperature, water content, thixotrophy and type and concentration of ions in the pore and eroding fluids are the factors that affect the critical shear stress required to initiate erosion. The osmotic influences and the structure of clay produce swelling of clay surface because of the difference in the concentration between the pore and eroding fluid. The interparticle bonding forces are reduced by the swelling and this is a factor in the erosion of cohesive soils by water. The swelling caused by the concentration gradients existing at a clay-water interface will be greater if the soil system is more dispersed. The erosion is accelerated by a process called slaking in partially saturated soils. The slaking is due to excess air pressure in the capillaries because of surface tension force in partially saturated soil. The pressure exerted by the entrapped air in the pores break loose small bits of soil on the surface. The slaking is more for the highly flocculated and low plasticity soils [2].

\section{Determination of Dispersion of Soil}

Visual classification, Atterberg's limits and particle size analysis do not provide a basis for differentiation between dispersive clays and ordinary erosion resistant clays [5]. The conventional laboratory tests performed to determine the dispersive clays includes pinhole test and double hydrometer test.
In the pinhole test, distilled water is allowed to flow through a $1.0 \mathrm{~mm}$ diameter hole drilled through a compacted specimen. The water becomes muddy and the hole rapidly erodes in dispersive clays. For nondispersive clays the water is clear and there is no erosion. The pinhole test is considered most reliable but it is important that the samples correctly simulate the soil state and the water composition expected in the field [5].

The soil conservation service laboratory dispersion test, also known as the double hydrometer test is one of the first methods developed to assess dispersion of clay soils. The current test method was developed in 1937 from a procedure proposed by Volk [7]. The particle size distribution is first determined using the standard hydrometer test in which the soil specimen is dispersed in distilled water with a chemical dispersant. A parallel hydrometer test is then made on a duplicate soil specimen, but without a chemical dispersant. The percent dispersion is the ratio of the dry mass of particles smaller than $0.005 \mathrm{~mm}$ diameter of the test without dispersing agent to the test with dispersing agent expressed as a percentage. Procedures for performing the test are outlined in USBR 5405, Determining Dispersibility of Clayey soils by the Double Hydrometer Test Method. The criteria for evaluating degree of dispersion using results from the double hydrometer test are shown in Table 1. Test results indicate that a high percentage of soils with dispersive characteristics, exhibited 30 percent or more dispersion when tested by this method.

The use of other methods such as shrinkage limit and unconfined compression strength test to characterize the dispersivity of the soil has been explored in the present study.

\section{Soil Used}

The soil used in present study locally called Suddha soil is present in Southern parts of Karnataka. It is wide spread below a depth of $1.5 \mathrm{~m}$ from the ground level and extends to depths greater than $10 \mathrm{~m}$. It possesses good strength in dry condition and upon increase in moisture content looses strength. Many failures have been observed along canal slopes, road bases, and foundations at sites where Suddha soil is present. This soil is silty sand with clay percent less than 20. This is considered as a problematic soil in view of wide spread damage under

Table 1. Degree of dispersion from double hydrometer test.

\begin{tabular}{cc}
\hline Percent dispersion & Degree of dispersion \\
\hline$<30$ & Non-dispersive \\
30 to 50 & Intermediate \\
$>50$ & Dispersive \\
\hline
\end{tabular}


saturated conditions. To know the nature and type of problem with the soil its properties are determined. Table 2 shows the Geotechnical properties of Suddha soil.

\section{Effect of Water Content on the Strength of Suddha Soil}

The unconfined compressive strength of Suddha soil has been determined for soil compacted with different water contents with the same compactive effort. It is seen very clearly from Figure 1 that the strength of soil decreases steeply with increase in molding water content. However, initially the strength increases with increase in molding water content due to increase in maximum dry density. But beyond the optimum moisture content there is very steep reduction in strength.

\section{Double Hydrometer Tests for Determination of Dispersion}

The double hydrometer test was conducted on Suddha soil. Figure 2 shows the results of double hydrometer test conducted on Suddha soil. The results indicate that Suddha soil has dispersion percent of about 35 percent. Thus it indicates that this soil's degree of dispersion is in the intermediate range.

\section{Shrinkage Limit Test as a Measure of Dispersivity}

The shrinkage limit is the water content where further loss of moisture will not result in any more volume reduction.The shrinkage limit of a natural soil is primarily a result of the packing phenomenon, which in turn is governed by the grain-size distribution of the soil and the shrinkage limit of pure clays may be affected by the fabric also. Even though clay-sized particles play an important role in the shrinkage phenomenon, there is an optimum clay content at which the shrinkage limit of a soil can become minimum. It has been further illustrated that the shrinkage limit is not at all related to the plasticity characteristics of the soil. The effect of dispersion on the shrinkage limit of Suddha soil has been studied in this section. Shrinkage limit test was carried out on lime treated Suddha soil using 7.5 and 15 percent dispersing agent. The results are shown in Table 3.

It can be seen that the shrinkage limit of Suddha soil which is about 22 decreases to 20 percent with addition of 7.5 percent dispersing agent solution which further decreases to 16 percent when the dispersing agent concentration is increased to 15 percent. Addition of lime which induces flocculation of particles increases the shrinkage limit. The higher is the concentration of lime the higher is the shrinkage limit. With any lime content the shrinkage is more with lower dispersing agent. It is thus clear that Suddha soil loses strength due to disper-
Table 2. Geotechnical properties of Suddha soil.

\begin{tabular}{|c|c|c|}
\hline Sl. No. & Properties & Value \\
\hline \multirow{5}{*}{1} & Particle size analysis & \\
\hline & Gravel (\%) & 4 \\
\hline & Sand (\%) & 57 \\
\hline & Silt (\%) & 26 \\
\hline & Clay (\%) & 13 \\
\hline 2 & Liquid limit (\%) & 41 \\
\hline 3 & Plastic limit (\%) & 24 \\
\hline 4 & Plasticity index & 17 \\
\hline 5 & Shrinkage limit (\%) & 22 \\
\hline \multirow[t]{2}{*}{6} & Specific gravity & 2.6 \\
\hline & Compaction Characteristics & \\
\hline \multirow[t]{2}{*}{7} & Optimum Moisture Content (\%) & 14 \\
\hline & Maximum dry density $\left(\mathrm{kN} / \mathrm{m}^{3}\right)$ & 17.8 \\
\hline 8 & Soil Classification & SM \\
\hline
\end{tabular}

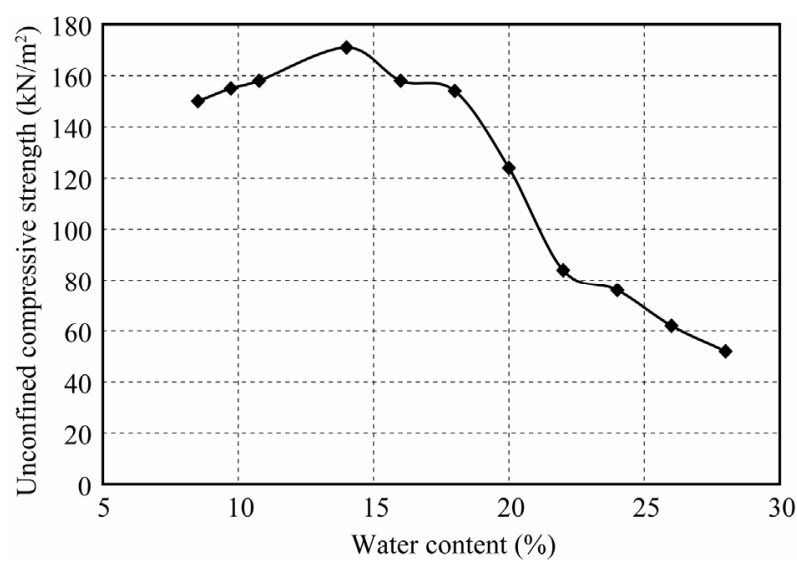

Figure 1. Effect of water content on the strength of Suddha soil.

sion of its particles.

\section{Unconfined Compression Strength Test as a Measure of Dispersivity}

It is clear from the above that the dispersivity of the soil particles can be reduced with the addition of lime which induces flocculation. The effect of varying amounts of lime on the unconfined strength of soil has been studied. For this purpose the cylindrical specimens were compacted at the optimum moisture content and maximum dry density of Suddha soil with and without dispersing 


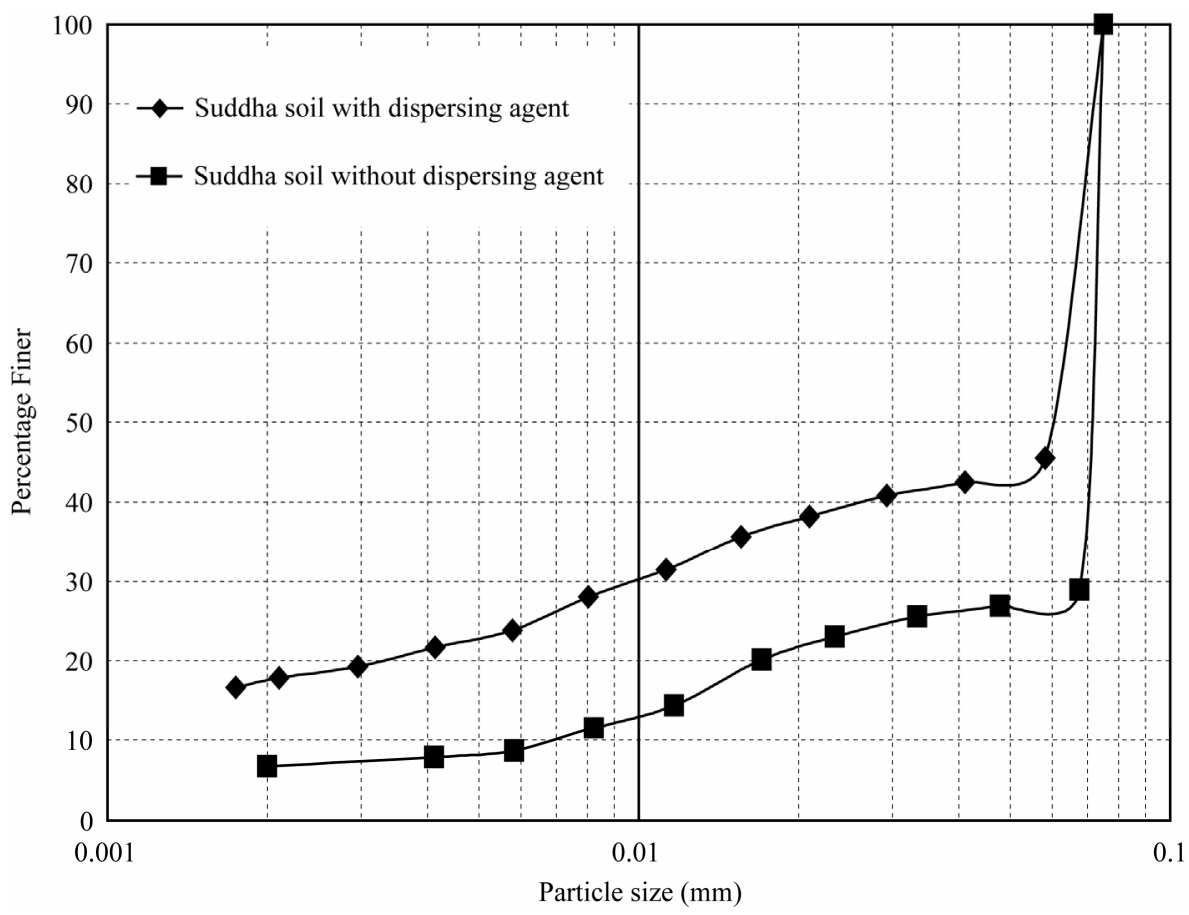

Figure 2. Double hydrometer test for Suddha soil.

Table 3. Shrinkage limit and specific gravity of Suddha soil using dispersing agent.

\begin{tabular}{ccccccc}
\hline & & \multicolumn{2}{c}{ with 7.5\% dispersing agent } & & \multicolumn{2}{c}{ with 15\% dispersing agent } \\
Sl. No. & \% Lime added & $\begin{array}{c}\text { Shrinkage limit } \\
\mathbf{( \% )}\end{array}$ & $\begin{array}{c}\text { Specific } \\
\text { gravity }\end{array}$ & & $\begin{array}{c}\text { Shrinkage limit } \\
\mathbf{( \% )}\end{array}$ & $\begin{array}{c}\text { Specific } \\
\text { gravity }\end{array}$ \\
\hline 1 & $\begin{array}{c}\text { No lime and no } \\
\text { Dispersing Agent }\end{array}$ & 22 & 2.6 & & 22 & 2.6 \\
2 & $0 \%$ & 20 & 2.54 & & 16 & 2.57 \\
3 & $1 \%$ & 32 & 2.58 & & 31 & 2.54 \\
4 & $2 \%$ & 34 & 2.59 & & 33 & 2.58 \\
5 & $3 \%$ & 36 & 2.59 & & 35 & 2.53 \\
6 & $6 \%$ & 39 & 2.59 & & 37 & 2.54 \\
\hline
\end{tabular}

agent and they were subjected to unconfined compressive strength test. The results are shown in Table 4. It is observed that the unconfined compressive strength increases with increase in lime content when Suddha soil was compacted with water. Addition of dispersing agent alone decreases the strength of soil greatly. Addition of any amount of lime increases the strength of soil with or without dispersing agent. But the increase is more when there is no dispersing agent. The dispersivity of soil with different lime content is calculated and summarized in Table 4.

It is clear from Table 5 that the dispersivity from the strength test is about 55 percent. It was earlier observed
Table 4. Unconfined compressive strength of Suddha soil with and without dispersing agent.

\begin{tabular}{|c|c|c|c|}
\hline Sl. No. & $\begin{array}{l}\% \text { Lime } \\
\text { added }\end{array}$ & $\begin{array}{l}\text { Unconfined compressive } \\
\text { strength, }\left(\mathrm{kN} / \mathrm{m}^{2}\right) \text { with } \\
\text { dispersing agent }\end{array}$ & $\begin{array}{l}\text { Unconfined compressive } \\
\text { strength, }\left(\mathrm{kN} / \mathrm{m}^{2}\right) \\
\text { without dispersing agent }\end{array}$ \\
\hline 1 & $0 \%$ & 77 & 171 \\
\hline 2 & $1 \%$ & 121 & 218 \\
\hline 3 & $2 \%$ & 148 & 246 \\
\hline 4 & $3 \%$ & 189 & 288 \\
\hline 5 & $6 \%$ & 206 & 305 \\
\hline
\end{tabular}


Table 5. Dispersivity of Suddha soil with different lime contents.

\begin{tabular}{ccc}
\hline Sl. No. & Lime content, \% & Dispersivity (\%) \\
\hline 1 & $0 \%$ & 54.9 \\
2 & $1 \%$ & 44.4 \\
3 & $2 \%$ & 39.8 \\
4 & $3 \%$ & 34.3 \\
5 & $6 \%$ & 32.4 \\
\hline
\end{tabular}

that the dispersivity of the soil is about 35 percent from the particle size analysis by double hydrometer tests with and without dispersing agent. The higher dispersivity from the strength tests clearly indicates that this method is more reliable than by particle size distribution method. The dispersivity of the soil goes on decreasing with increasing additions of lime. However, the dispersivity does not reduced below 30 percent. The very gradual decrease in dispersivity between 3 and 6 percent of lime shows the optimum lime content is about 3 percent.

\section{Conclusions}

The paper brings out that the dispersivity of soil can be assessed by comparing the values of results of various tests carried out on soil with and without dispersing agent. The dispersivity of the soil generally increases with the amount of dispersing agent. The dispersivity of the soil decreases after stabilizing the soil with lime. Among the various methods used such as double hydrometer, shrinkage limit and unconfined compression tests, the later method is more accurate and can generally be adopted for assessing the dispersivity of the soils.

\section{REFERENCES}

[1] J. L. Sherard, L. P. Dunnigan and R. S. Decker, "Identification and Nature of Dispersive Soils," ASCE Geotechnical Division, Vol. 102, No. 4, 1976, pp. 69-87.

[2] R. T. Heinzen and K. Arulanandan, "Factors Influencing Dispersive Clays and Methods of Identification,” ASTM Special Technical Publication, Vol. 623, 1977, pp. 202217.

[3] G. G. S. Holmgren and C. P. Flanagan, "Factors Affecting Spontaneous Dispersion of Soil Materials as Evidenced by the Crumb Test," ASTM Special Technical Publication, Vol. 623, 1977 pp. 219-239.

[4] B. Indraratna, et al., "Stabilization of a Dispersive Soil by Blending with Fly Ash,” Quarterly Journal of Engineering Geology, Vol. 24, 1991, pp. 275-290. doi:10.1144/GSL.QJEG.1991.024.03.03

[5] J. K. Mitchell, "Fundamentals of Soil Behavior," 2nd Edition, John Wiley \& Sons, Inc, Hoboken, 1993.

[6] S. Bhuvaneshwari, B. Soundra, R. G. Robinson and S. R. Gandhi, "Stabilization and Microstructural Modification of Dispersive Clayey Soils,” 1st International Conference on Soil and Rock Engineering, Srilankan Geotechnical Society, Columbo, Srilanka, 2007, pp. 1-7.

[7] G. M. Volk, "Method of Determination of the Degree of Dispersion of the Clay Fraction of Soils," Proceedings of Soil Science Society of America, Vol. 2, 1937, p. 561. 